Check for updates

Cite this: Sustainable Energy Fuels, 2018, 2, 2747

Received 18th August 2018 Accepted 4th October 2018

DOI: $10.1039 / \mathrm{c} 8 \mathrm{se} 00422 \mathrm{f}$

rsc.li/sustainable-energy

\section{Synthesis and investigation of tetraphenyltetrabenzoporphyrins for electrocatalytic reduction of carbon dioxide}

\author{
Dogukan H. Apaydin, (DD *a Engelbert Portenkirchner, (D) ${ }^{\mathrm{b}}$ Pichayada Jintanalert, ${ }^{\mathrm{c}}$ \\ Matthias Strauss, ${ }^{a}$ Jirapong Luangchaiyaporn, ${ }^{c}$ Niyazi Serdar Sariciftci (D) ${ }^{a}$ \\ and Patchanita Thamyongkit (D) ${ }^{d}$
}

\begin{abstract}
We report the synthesis and electrochemical properties of freebase tetraphenyltetrabenzoporphyrin and its complexes of $\mathrm{Zn}(॥), \mathrm{Co}(॥), \mathrm{Ni}(॥), \mathrm{Cu}(॥)$ and $\mathrm{Sn}(\mathrm{IV})$ towards electrochemical reduction of carbon dioxide $\left(\mathrm{CO}_{2}\right)$. Based on cyclic voltammetry, it is shown that central metals significantly affect the electrocatalytic performance in the reduction of $\mathrm{CO}_{2}$ in terms of reduction potential and catalytic current enhancement. At an applied potential of $-1.90 \mathrm{~V}$ vs. an $\mathrm{Ag} / \mathrm{AgCl}$ quasi reference electrode for $20 \mathrm{~h}$, the electrocatalytic reduction of $\mathrm{CO}_{2}$ realized by $\mathrm{Zn}(॥)$ - and $\mathrm{Cu}(॥)$-tetraphenyltetrabenzoporphyrins to carbon monoxide resulted in faradaic efficiencies of around $48 \%$ and $33 \%$, respectively.
\end{abstract}

\section{Introduction}

Rapid global economic and population growth has led to an increase in fuel consumption in industrial, transportation, commercial and residential sectors. As a major source of energy, vast quantities of fossil fuels are burnt, creating environmental problems due to subsequent creation of greenhouse gases and pollutants. A greenhouse relevant product from fuel combustion processes is carbon dioxide $\left(\mathrm{CO}_{2}\right)$. Therefore, assiduous scientific attention is directed towards identification of optimal methods to reduce the generation of $\mathrm{CO}_{2}$ and, at the same time, to convert $\mathrm{CO}_{2}$ into other useful compounds. One way to address this issue might be the cyclic use of carbon in human society, which stabilizes the $\mathrm{CO}_{2}$ content in the atmosphere.

The electrochemical reduction processes of $\mathrm{CO}_{2}$ using catalysts have attracted much attention because they require lower overpotential, compared to the direct reduction of $\mathrm{CO}_{2}$, and provide higher product selectivity. ${ }^{1-5}$ As economically friendly substitutes for precious-metal catalysts, organometallic electrocatalysts have become popular. ${ }^{6-13}$ Among such materials, porphyrin derivatives have been investigated continuously as potential electrochemical catalysts for the reduction of $\mathrm{CO}_{2} \cdot{ }^{14,15}$ The great advantages of porphyrin compounds regarding this

\footnotetext{
${ }^{a}$ Linz Institute for Organic Solar Cells (LIOS), Institute of Physical Chemistry, Johannes Kepler University Linz, 4040 Linz, Austria. E-mail: dogukan.apaydin@jku.at; dogukanhazar.apaydin@ist.ac.at

${ }^{b}$ Institute of Physical Chemistry, University of Innsbruck, 6020 Innsbruck, Austria 'Department of Chemistry, Faculty of Science, Chulalongkorn University, 10330 Bangkok, Thailand

${ }^{d}$ Research Group on Materials for Clean Energy Production STAR, Department of Chemistry, Faculty of Science, Chulalongkorn University, 10330 Bangkok, Thailand
}

application originate from their high stability and tunability of their electrochemical properties by changing metal centers and substituents at the macrocyclic peripheral positions. Such structural modifications do not only enable improvement in the electrocatalytic performance of the systems, but also allow one to investigate the possible catalytic mechanisms. ${ }^{16-19}$

Tetrabenzoporphyrins are one of the very intriguing porphyrin derivatives that exhibit unique photophysical and electrochemical behaviors caused by extension of a $\pi$-conjugated structure at the $\beta$-positions of the porphyrin core and highly distorted macrocycle core due to meso-substitutions. ${ }^{20-24}$ Our previous work described systematic investigation of the photophysical and electrochemical properties of meso-substituted porphyrin and benzoporphyrin derivatives as ternary components for highly efficient bulk-heterojunction solar cells. ${ }^{22}$ Our observations on the electrochemical properties of the mesosubstituted benzoporphyrin derivatives obtained from the previous study have led to extended investigation towards their catalytic activities for the electrochemical reduction of $\mathrm{CO}_{2}$ in this work. To the best of our knowledge, until now there are only a few studies on the electrochemical properties and catalysis of benzoporphyrin derivatives for $\mathrm{CO}_{2}$ reduction. Ramirez et al. described the electrochemical and photoelectrochemical reduction of $\mathrm{CO}_{2}$ using a $\mathrm{Co}(\mathrm{II})$-tetrabenzoporphyrin-modified electrode. ${ }^{25,26}$ To gain insights into the electrochemical properties of benzoporphyrins towards the electrochemical reduction of $\mathrm{CO}_{2}$, a series of metal-free and metallated tetraphenyltetrabenzoporphyrins as shown in Chart 1 were synthesized, characterized and investigated for their electrocatalytic activities for the reduction of $\mathrm{CO}_{2}$. Complexes of interest for this study had non-precious-metal centers like $\mathrm{Zn}(\mathrm{II})-, \mathrm{Co}(\mathrm{II})-, \mathrm{Ni}$ (II)-, $\mathrm{Cu}(\mathrm{II})$ - and $\mathrm{Sn}(\mathrm{rv})-$, which were previously studied in porphyrin analogs for 


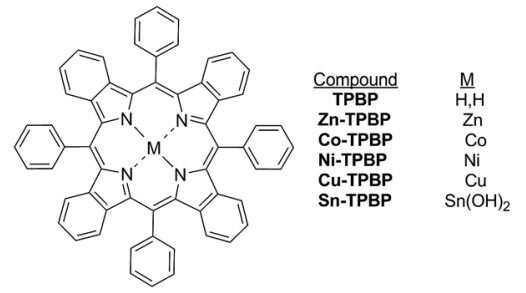

Chart 1 Chemical structure of the benzoporphyrins.

the electrochemical reduction of $\mathrm{CO}_{2} \cdot{ }^{27-31}$ The overview presented in this work on the effect of the central metals on the electrochemical behavior and electrocatalytic activities of these benzoporphyrins for the reduction of $\mathrm{CO}_{2}$ will become a useful guideline for further development of several precious-metal-free oligopyrrole-based electrocatalytic systems.

\section{Results and discussion}

\section{Synthesis}

Synthesis of the benzoporphyrins started from previously reported demetallation of $\mathbf{C} \mathbf{U}-\mathbf{T P B P}^{32}$ by sulfuric acid at room temperature for $30 \mathrm{~min}$, resulting in TPBP in $81 \%$ yield (Scheme 1). ${ }^{33}$ In its ${ }^{1} \mathrm{H}$-NMR spectrum, a broad singlet signal of two inner protons at $\delta-1.17 \mathrm{ppm}$ confirmed the formation of TPBP. To obtain the desired metallated benzoporphyrins, TPBP was reacted with $\mathrm{Zn}(\mathrm{OAc})_{2} \cdot 2 \mathrm{H}_{2} \mathrm{O},{ }^{34} \mathrm{Co}(\mathrm{OAc})_{2} \cdot 4 \mathrm{H}_{2} \mathrm{O}^{35}$ and $\mathrm{SnCl}_{2} \cdot 2 \mathrm{H}_{2} \mathrm{O}^{36}$ as described in the previous studies, leading to Zn-TPBP, Co-TPBP and Sn-TPBP, respectively, in $80-97 \%$ yield. Complete metallation of TPBP in these reactions was monitored by the absence of the broad singlet signal of the benzoporphyrinic inner protons at $\delta-1.17 \mathrm{ppm}$ in the ${ }^{1} \mathrm{H}-\mathrm{NMR}$ spectra and disappearance of the characteristic emission peak of TPBP at $787 \mathrm{~nm}$. HR-ESI-MS confirmed the formation of both Zn-TPBP and Co-TPBP by showing their molecular ion peaks at $\mathrm{m} / \mathrm{z} 876.2231$ and 871.2273, respectively. Due to difficulties in chromatographic purification, Sn-TPBP could not be completely separated from other byproducts and was obtained in $>90 \%$ purity based on ${ }^{1} \mathrm{H}-\mathrm{NMR}$ spectroscopy. However, its formation could be confirmed by MALDI-TOF MS showing its molecular ion peak at $m / z$ 966.292. Ni-TPBP was obtained from a known procedure described in detail by Finikova et al. ${ }^{32}$

\section{Photophysical properties}

As mentioned above, variation of the metal center of the benzoporhyrin derivatives does not only significantly affect the electrochemical behavior, but also the photophysical properties of the molecules. Therefore, absorption and emission of TPBP, Zn-TPBP, Co-TPBP, Ni-TPBP, Cu-TPBP and Sn-TPBP were investigated in this study to provide additional information that should be useful for further applications of these materials in optoelectronics and photoelectrocatalysis. By using UV-Vis spectrophotometry, normalized absorption spectra of all compounds in toluene were obtained as shown in Fig. 1. All compounds exhibited characteristic absorption patterns of the metallated benzoporphyrins having intense Soret bands in the

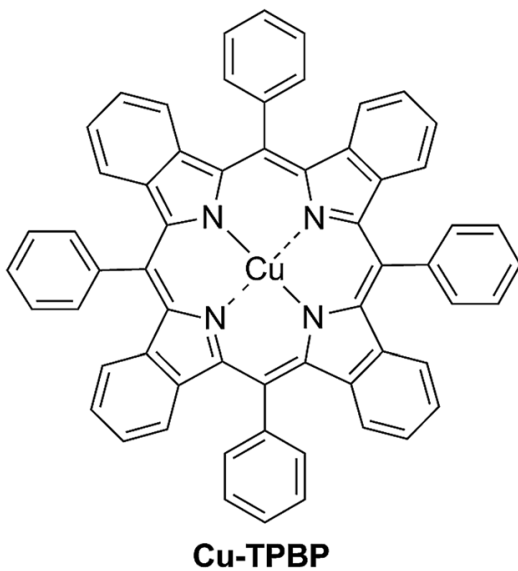

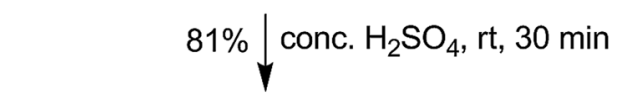<smiles></smiles>

TPBP

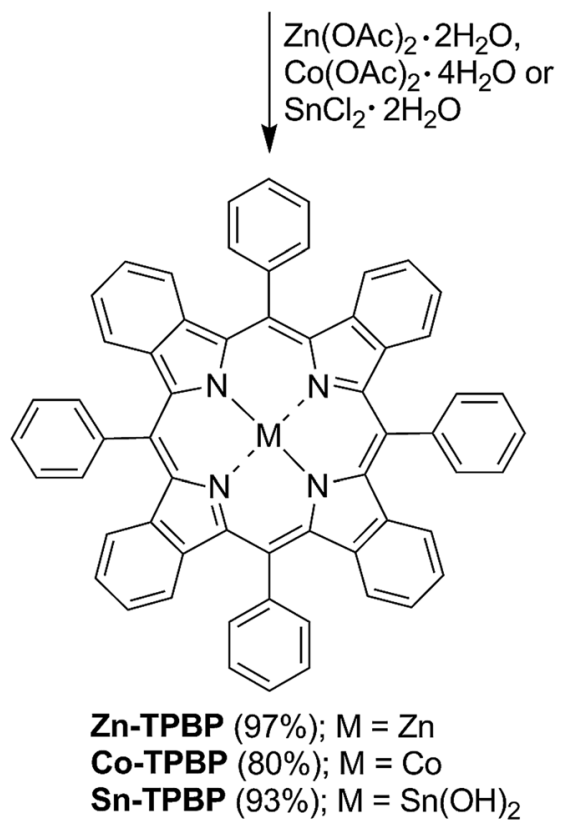

Scheme 1 Synthesis of Zn-TPBP, Co-TPBP and Sn-TPBP.

range of 446-466 $\mathrm{nm}$ with absorption coefficients $(\varepsilon)$ of $1.6 \times$ $10^{5}-5.3 \times 10^{5} \mathrm{M}^{-1} \mathrm{~cm}^{-1}$, and the Q-bands in the range of 592$698 \mathrm{~nm}$, as summarized in Table 1. Upon excitation at their absorption maxima, TPBP, Zn-TPBP and Sn-TPBP showed 


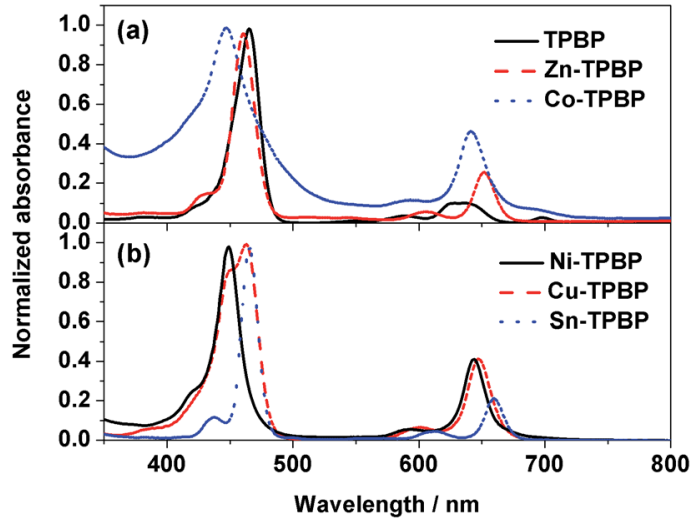

Fig. 1 Normalized absorption spectra of (a) TPBP (black solid line), $\mathrm{Zn}$-TPBP (red dashed line) and Co-TPBP (blue dotted line), and (b) Ni-TPBP (black solid line), and Cu-TPBP (red dashed line).

Table 1 Absorption and emission spectral data of the benzoporphyrins

\begin{tabular}{lll}
\hline Compound & $\lambda_{\mathrm{abs}} / \mathrm{nm}\left(\varepsilon \times 10^{5} / \mathrm{M}^{-1} \mathrm{~cm}^{-1}\right)$ & $\lambda_{\mathrm{em}} / \mathrm{nm}$ \\
\hline TPBP & $465(5.3), 588^{a}, 626^{a}, 640^{a}, 698^{a}$ & 720,787 \\
Zn-TPBP & $461(2.8), 607^{a}, 652^{a}$ & 658,724 \\
Co-TPBP & $446(1.7), 595^{a}, 640(0.8)$ & $-{ }^{b}$ \\
Ni-TPBP & $449(2.2), 592^{a}, 644(0.9)$ & $-^{b}$ \\
Cu-TPBP & $449(1.6), 463(1.9), 601(0.1), 648(0.8)$ & $-^{b}$ \\
Sn-TPBP & $430(0.3), 466(4.1), 612^{a}, 660(0.9)$ & 665,745
\end{tabular}

${ }^{a}$ Due to low absorption, the $\varepsilon$ value could not be determined. ${ }^{b}$ No emission peak was observed.

emission peaks in the range of $658-787 \mathrm{~nm}$ as shown in Fig. 2 and Table 1, while Ni-TPBP, Cu-TPBP and Co-TPBP gave no significant emission.

\section{Electrochemical characterization and catalytic activity}

All benzoporphyrins were studied by means of cyclic voltammetry to evaluate their catalytic activities towards electrochemical $\mathrm{CO}_{2}$ reduction. The cyclic voltammograms were recorded in the potential range of $0.0 \mathrm{~V}$ to $-2.0 \mathrm{~V}$ from a $0.1 \mathrm{M}$

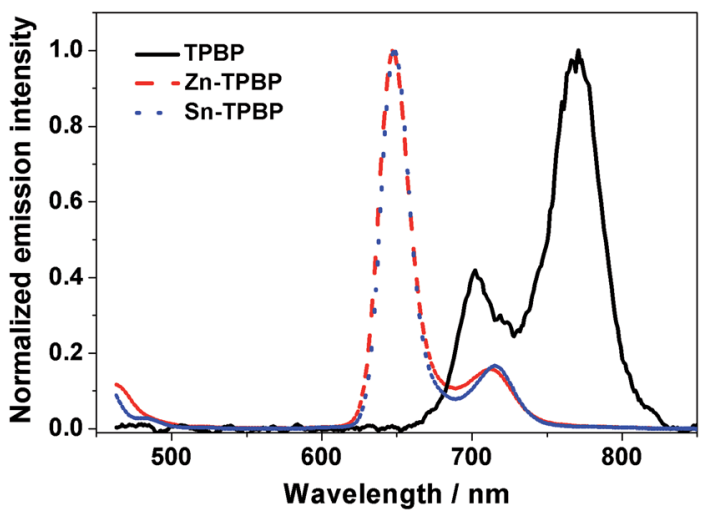

Fig. 2 Normalized emission spectra of TPBP (black solid line), Zn-TPBP (red dashed line) and Sn-TPBP (blue dotted line).
$\mathrm{TBAPF}_{6}$ solution in DMF containing $1.0 \mathrm{mM}$ benzoporphyrin with a scan rate of $50 \mathrm{mV} \mathrm{s}^{-1}$ under the $\mathrm{N}_{2}$ - and $\mathrm{CO}_{2}$-saturated conditions at ambient temperature and pressure. Fig. 3a shows that under the $\mathrm{N}_{2}$-saturated conditions, the first and the second reduction steps of TPBP are characterized by reversible reduction peaks at $-1.22 \mathrm{~V}$ and $-1.52 \mathrm{~V}$, respectively. However, when the solution of TPBP was saturated with $\mathrm{CO}_{2}$, the first irreversible reduction was also observed at $-1.22 \mathrm{~V}$ with a two-fold increase in peak current from $0.04 \mathrm{~mA}$ to $0.08 \mathrm{~mA}$, while its second irreversible reduction peak appeared at $-1.84 \mathrm{~V}$ with a negative shift by $0.32 \mathrm{~V}$ and a peak current enhancement from $0.05 \mathrm{~mA}$ to $0.13 \mathrm{~mA}$. The great difference in the electrochemical behavior of TPBP observed in this case, compared with that under the $\mathrm{N}_{2}$-saturated conditions, may be attributed to possible binding between $\mathrm{CO}_{2}$ and inner pyrrolenine nitrogen atoms of the freebase benzoporphyrin macrocycle. The binding $\mathrm{CO}_{2}$ might form an ionic salt that is stabilized by the TBA cation which may present itself as a peak at more negative potentials. Moreover, new anodic signals were observed in the potential range of $-0.40 \mathrm{~V}$ to $-0.80 \mathrm{~V}$, indicating the generation of unknown products from the irreversible reduction process(es) or the release of captured carbon dioxide. As for the electrochemical reduction of Zn-TPBP (Fig. 3b), a fully reversible first reduction (around $-1.6 \mathrm{~V}$ ) and as suggested by the scan-rate dependency of the peak current, a quasi-reversible second reduction peak (around $-1.8 \mathrm{~V}$ ) can be observed under $\mathrm{N}_{2}$-saturated conditions. A slight current increase for the first reduction peak and a two-fold current increase (from $0.05 \mathrm{~mA}$ to $0.10 \mathrm{~mA}$ ) for the second one were monitored under $\mathrm{CO}_{2}$-saturated conditions signaling the reduction of $\mathrm{CO}_{2}$. Unknown oxidation signals were found under both $\mathrm{N}_{2}$ - and $\mathrm{CO}_{2}$-saturated conditions in the potential range of $-0.30 \mathrm{~V}$ to $-0.70 \mathrm{~V}$, which may be attributed to the side products formed during the reduction process. This observation of the increase in current and the change in the shape of the second ligand-based peak suggested that the doubly-reduced $\mathbf{Z n - T P B P}$ is the responsible molecule for the reduction of $\mathrm{CO}_{2}$.

The cyclic voltammogram of Co-TPBP in the $\mathrm{N}_{2}$-saturated solution revealed a reversible reduction peak at $-0.75 \mathrm{~V}$ stemming from the metal-centered reduction of the molecule. This was followed by two quasi-reversible peaks at $-1.29 \mathrm{~V}$ and $-1.55 \mathrm{~V}$ which may be attributed to the multi-step ligandcentered reduction of the meso-substituted benzoporphyrin macrocycle (Fig. 3c). Under the $\mathrm{CO}_{2}$-saturated conditions, Co-TPBP showed a very similar reduction pattern with a slight current increase. Compared with planar porphyrin and phthalocyanine derivatives reported as potential catalysts. ${ }^{37}$ The difference in the catalytic behavior of Co-TPBP observed herein should stem from the unique saddle-shaped macrocycle distortion of the metallated benzoporphyrins previously studied by several groups. ${ }^{20-24}$

The cyclic voltammogram of Ni-TPBP under the $\mathrm{N}_{2}$-saturated conditions showed the first reversible reduction peak at $-1.10 \mathrm{~V}$ which is ligand-centred and the second quasi-reversible one at $-1.90 \mathrm{~V}$ that originates from metal-centered reduction. ${ }^{38}$ (Fig. 3d). Under the $\mathrm{CO}_{2}$-saturated conditions, similar electrochemical features were observed with a 3.6-fold current 

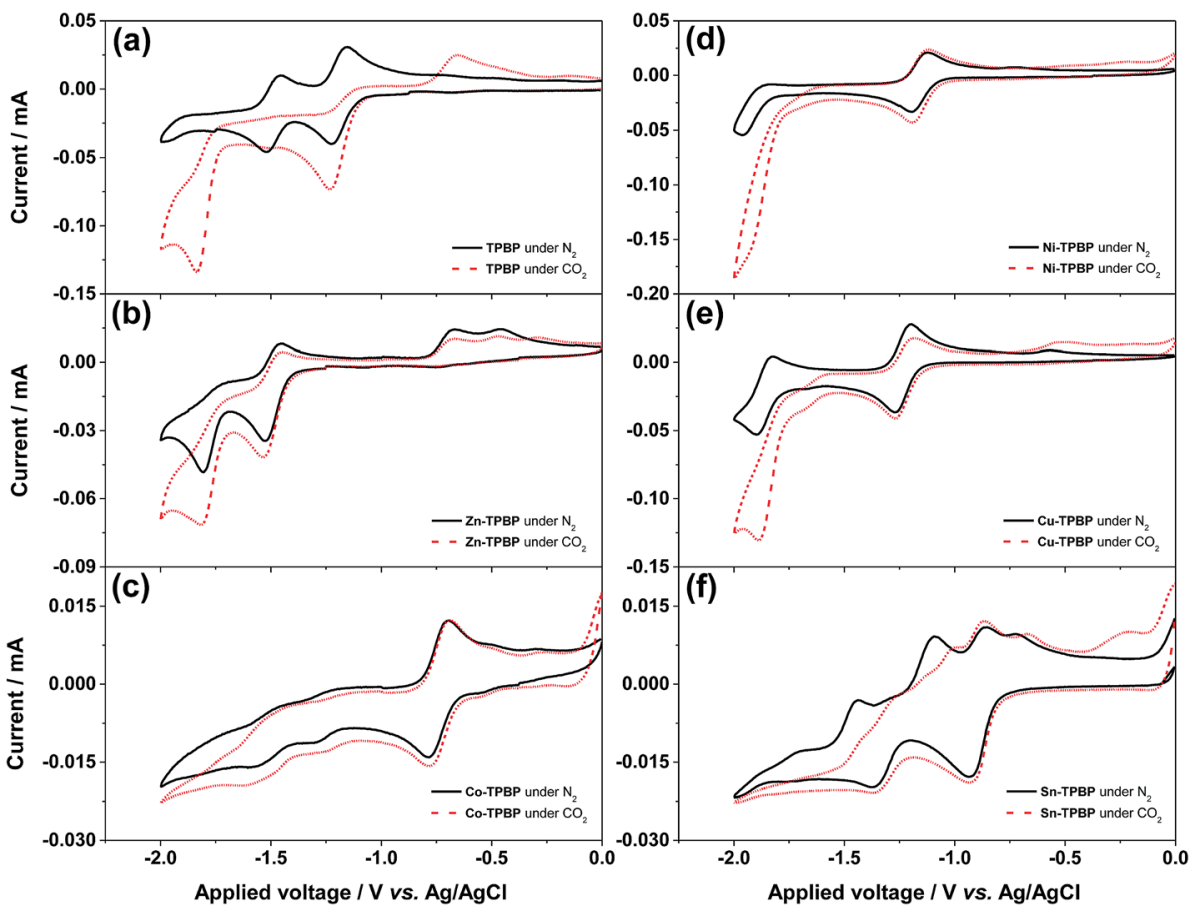

Fig. 3 Cyclic voltammograms of a $0.1 \mathrm{M} \mathrm{TBAPF}_{6}$ solution in DMF containing $1.0 \mathrm{mM}$ (a) TPBP, (b) Zn-TPBP, (c) Co-TPBP, (d) Ni-TPBP, (e) CuTPBP and (f) Sn-TPBP under the $\mathrm{N}_{2}$-(black solid line) and $\mathrm{CO}_{2}$-saturated (red dashed line) conditions recorded at a scan rate of $50 \mathrm{mV} \mathrm{s}{ }^{-1}$ in the potential range of 0.00 to $-2.00 \mathrm{~V}$

enhancement of the second reduction from $0.05 \mathrm{~mA}$ to $0.18 \mathrm{~mA}$ and a positive shift of its onset potential $\left(E_{\text {onset }}\right)$ by $0.20 \mathrm{~V}$, suggesting the catalytic activity of Ni-TPBP towards the electrochemical reduction of $\mathrm{CO}_{2}$. In a similar manner, the $\mathrm{N}_{2}^{-}$ saturated solution of Cu-TPBP exhibited two major reversible reduction peaks at $-1.27 \mathrm{~V}$ and $-1.90 \mathrm{~V}$ which are attributed to the formation of a dianion radical and dianion of the macrocycle, respectively as shown in Fig. 3e. ${ }^{38,39}$ In the presence of $\mathrm{CO}_{2}$, a considerable current increase from $0.05 \mathrm{~mA}$ to $0.13 \mathrm{~mA}$ was observed at $-1.85 \mathrm{~V}$ with a positive shift of $E_{\text {onset }}$ by $0.18 \mathrm{~V}$, suggesting the catalytic activity of Cu-TPBP for the electrochemical reduction of $\mathrm{CO}_{2}$. Sn-TPBP showed rather complex electrochemical behavior with two major reduction peaks at $-0.92 \mathrm{~V}$ and $-1.36 \mathrm{~V}$, followed by at least five anodic peaks under the $\mathrm{N}_{2}$-saturated conditions, suggesting irreversible structural changes of the molecules upon the reduction processes (Fig. 3f). In the presence of $\mathrm{CO}_{2}$, its cyclic voltammogram also exhibited two main reduction peaks at a similar peak potential with even more complex anodic signals and a negligible current enhancement. This was attributed to possible interaction of the axial hydroxyl ligands of Sn-TPBP and $\mathrm{CO}_{2}$ that might lead to unexpected formation of side products upon reduction.

To further investigate the electrocatalytic performance of each benzoporphyrin towards the electrochemical reduction of $\mathrm{CO}_{2}$, all compounds were subjected to constant-potential electrolysis at an applied potential of $-1.90 \mathrm{~V}$ for $20 \mathrm{~h}$. The results from GC headspace analysis showed that the $\mathrm{CO}_{2}$-saturated electrolyte solutions containing TPBP, Co-TPBP, Ni-TPBP and Sn-TPBP did not yield any detectable reduction product. In the case of TPBP, it is likely that the above-mentioned binding between $\mathrm{CO}_{2}$ and the benzoporphyrin core was relatively strong and therefore suppressed the favorable reduction process of $\mathrm{CO}_{2}$ molecules. The low current enhancement observed for the above-described cyclic voltammograms of Co-TPBP and Sn-TPBP under the $\mathrm{CO}_{2}$ atmosphere could imply their low catalytic efficiencies for the electrochemical reduction of $\mathrm{CO}_{2}$. As for Ni-TPBP, although the current enhancement was found to be quite high in the cyclic voltammetry study, the reduction process did not lead to any detectable amount of $\mathrm{CO}$ or any other gaseous products. It is possible that the reduction process proceeded via other mechanisms and further optimization of the reduction conditions, such as addition of proton sources, $\mathrm{pH}$ adjustment and use of a co-catalyst, may be required. When Zn-TPBP and Cu-TPBP were used as catalysts, $8.67 \mu \mathrm{mol}$ and $12 \mu \mathrm{mol}$ of $\mathrm{CO}$ were detected, corresponding to a faradaic efficiency of $33 \%$ and $48 \%$ with turnover numbers of 1.7 and 6.6, respectively.

\section{Conclusions}

Six tetraphenyltetrabenzoporphyrins, including the freebase derivative and the metal-chelated ones having $\mathrm{Zn}, \mathrm{Co}, \mathrm{Ni}, \mathrm{Cu}$ and Sn metal centers, were successfully synthesized and characterized. According to UV-visible and fluorescence spectrophotometry, and cyclic voltammetry, the introduction and variation of the metal centers obviously affected the photophysical properties, electrochemical behaviors and catalytic activities for the electrochemical reduction of $\mathrm{CO}_{2}$ to $\mathrm{CO}$. The results from cyclic voltammetry showed that, compared with the 
$\mathrm{N}_{2}$-saturated conditions, TPBP, Ni-TPBP, Zn-TPBP and Cu-TPBP exhibited a significant current enhancement, while Co-TPBP and Sn-TPBP gave only a slight increase in the peak current when $\mathrm{CO}_{2}$ was introduced into the solution. The constant-potential electrolysis revealed the formation of $\mathrm{CO}$ as the main reduction product with faradaic efficiencies of $33 \%$ and $48 \%$ and turnover numbers of 1.7 and 6.6 for Zn-TPBP and Cu-TPBP, respectively. This study suggests that, among the metallobenzoporphyrins of interest, $\mathrm{Zn}$ - and $\mathrm{Cu}$-chelated analogs exhibited superior electrocatalytic activities towards the electrochemical reduction of $\mathrm{CO}_{2}$ to $\mathrm{CO}$. Here, we show the catalytic potential of the metallated benzoporphyrins as alternative $\mathrm{CO}_{2}$ reduction catalysts using cheaper and more abundant metal centers like $\mathrm{Zn}$ and $\mathrm{Cu}$, compared to Re and Pd. Optimization of the reduction conditions, together with structural modification of benzoporphyrin ligands will be further studied and described elsewhere.

\section{Experimental section}

\section{Materials and methods}

All chemicals were of analytical grade, purchased from commercial suppliers and used as received without further purification. ${ }^{1} \mathrm{H}-\mathrm{NMR}$ and ${ }^{13} \mathrm{C}-\mathrm{NMR}$ spectra were obtained in deuterated chloroform $\left(\mathrm{CDCl}_{3}\right)$ at 400 megahertz $(\mathrm{MHz})$ for ${ }^{1} \mathrm{H}$ nuclei and $100 \mathrm{MHz}$ for ${ }^{13} \mathrm{C}$ nuclei. Chemical shifts $(\delta)$ are reported in parts per million (ppm) relative to the residual $\mathrm{CHCl}_{3}$ peak (7.26 ppm for ${ }^{1} \mathrm{H}-\mathrm{NMR}$ and $77.0 \mathrm{ppm}$ for ${ }^{13} \mathrm{C}-\mathrm{NMR}$ spectroscopy). Mass spectra were obtained using high-resolution electron spray ionization mass spectrometry (HR-ESI-MS) and matrix-assisted laser desorption ionization-time of flight mass spectrometry (MALDI-TOF MS) with dithranol as a matrix. Ultraviolet-visible (UV-vis) and fluorescence spectrophotometry were performed in toluene at room temperature. Molar extinction coefficients $(\varepsilon)$ are expressed in $\mathbf{M}^{-1} \mathrm{~cm}^{-1}$.

\section{Non-commercial compounds}

meso-tetraphenyltetrabenzoporphyrinatonickel(II) (Ni-TPBP $)^{32}$ and meso-tetraphenyltetrabenzoporphyrinatocopper(II) $\quad$ (Cu-TPBP) ${ }^{32}$ were prepared by a published procedure.

\section{Synthesis and characterization of benzoporphyrin derivatives}

meso-Tetraphenyltetrabenzoporphyrin (TPBP). Following a previously published procedure, ${ }^{33} \mathbf{C u}^{-\mathbf{T P B P}^{32}}(0.052 \mathrm{~g}$, $0.060 \mathrm{mmol}$ ) was reacted with concentrated sulfuric acid $(10 \mathrm{~mL})$ at room temperature for $30 \mathrm{~min}$. The resulting reaction mixture was poured into a water/ice mixture and then extracted with dichloromethane. The combined organic phase was dried over anhydrous $\mathrm{Na}_{2} \mathrm{SO}_{4}$ and concentrated to dryness. The crude mixture was purified by column chromatography (silica gel, $\mathrm{CH}_{2} \mathrm{Cl}_{2} /$ hexanes $\left.(2: 1)\right)$ to afford TPBP as a green solid $(0.039 \mathrm{~g}$, 81\%). ${ }^{1} \mathrm{H}-\mathrm{NMR}: \delta_{\mathrm{H}}-1.17(\mathrm{~s}, 2 \mathrm{H}), 7.34-7.43(\mathrm{~m}, 8 \mathrm{H}), 7.82-8.02$ $(\mathrm{m}, 16 \mathrm{H}), 8.37(\mathrm{~d}, J=7.6 \mathrm{~Hz}, 4 \mathrm{H}), 8.56(\mathrm{~d}, J=7.2 \mathrm{~Hz}, 8 \mathrm{H})$; ${ }^{13} \mathrm{C}-\mathrm{NMR}: \delta_{\mathrm{C}} 114.5,115.8,124.3,124.7,125.9,128.6,129.0$, $129.3,129.5,130.1,131.5,134.7,136.2,139.9$, 141.5, 142.1; MALDI-TOF-MS $\mathrm{m} / \mathrm{z}$ (\%): found 814.554 (100) $\left[\mathrm{M}^{+}\right]$; calcd $814.971\left(\mathrm{M}=\mathrm{C}_{60} \mathrm{H}_{38} \mathrm{~N}_{4}\right)$; HR-ESI-MS $m / z:[\mathrm{M}+\mathrm{H}]^{+}$calcd for $\mathrm{M}=\mathrm{C}_{60} \mathrm{H}_{38} \mathrm{~N}_{4}, 815.3175$; found 815.3174; $\lambda_{\mathrm{abs}}\left(\varepsilon \times 10^{5}\right)$ $465(5.3), 588,626,640,698 \mathrm{~nm} ; \lambda_{\mathrm{em}}\left(\lambda_{\mathrm{ex}}=465 \mathrm{~nm}\right) 720,787 \mathrm{~nm}$.

meso-Tetraphenyltetrabenzoporphyrinatozinc (Zn-TPBP). Following a previously published procedure, ${ }^{34}$ a solution of TPBP $(0.131 \mathrm{~g}, 0.161 \mathrm{mmol})$ in chloroform $(117 \mathrm{~mL})$ was reacted with a solution of $\mathrm{Zn}(\mathrm{OAc})_{2} \cdot 2 \mathrm{H}_{2} \mathrm{O}(0.177 \mathrm{~g}, 0.805 \mathrm{mmol})$ in methanol $(13 \mathrm{~mL})$ at room temperature for $12 \mathrm{~h}$. After that, the resulting mixture was washed with water, and the organic layer was separated and dried over anhydrous $\mathrm{Na}_{2} \mathrm{SO}_{4}$. After removal of the solvent, the crude mixture was purified by column chromatography (silica gel, $\mathrm{CH}_{2} \mathrm{Cl}_{2} /$ hexanes $(2: 1)$ ) to afford Zn-TPBP as a greenish blue solid $(0.136 \mathrm{~g}, 97 \%) .{ }^{1} \mathrm{H}-\mathrm{NMR}$ : $\delta_{\mathrm{H}}$ $7.16(\mathrm{dd}, J=6.0,2.8 \mathrm{~Hz}, 8 \mathrm{H}), 7.28(\mathrm{dd}, J=6.0,2.8 \mathrm{~Hz}, 8 \mathrm{H}) 7.86$ $(\mathrm{t}, J=7.2 \mathrm{~Hz}, 8 \mathrm{H}), 7.93(\mathrm{t}, J=7.2 \mathrm{~Hz} 4 \mathrm{H}), 8.30(\mathrm{~d}, J=7.2 \mathrm{~Hz}, 8 \mathrm{H})$; ${ }^{13} \mathrm{C}-\mathrm{NMR}: \delta_{\mathrm{C}} 117.3$, 124.3, 124.4, 125.5, 128.8, 129.0, 129.1, 132.7, 134.1, 134.2, 138.6, 143.2, 143.4; MALDI-TOF-MS $m / z(\%)$ : found $875.913(100)\left[\mathrm{M}^{+}\right]$, calcd $875.365\left(\mathrm{M}=\mathrm{C}_{60} \mathrm{H}_{36} \mathrm{~N}_{4} \mathrm{Zn}\right)$; HRESI-MS $m / z$ : $\left[\mathrm{M}^{+}\right]$calcd for $\mathrm{M}=\mathrm{C}_{60} \mathrm{H}_{36} \mathrm{~N}_{4} \mathrm{Zn}$, 876.2231; found $876.2231 ; \lambda_{\text {abs }}\left(\varepsilon \times 10^{5}\right) 461(2.8), 607,652 \mathrm{~nm} ; \lambda_{\text {em }}\left(\lambda_{\text {ex }}=461 \mathrm{~nm}\right)$ 658, $724 \mathrm{~nm}$.

meso-Tetraphenyltetrabenzoporphyrinatocobalt(Co-TPBP). Following a previously published procedure, ${ }^{35}$ a solution of TPBP (0.048 g, $0.059 \mathrm{mmol})$ in chloroform $(45 \mathrm{~mL})$ was reacted with a solution of $\mathrm{Co}(\mathrm{OAc})_{2} \cdot 4 \mathrm{H}_{2} \mathrm{O}(0.073 \mathrm{~g}, 0.30 \mathrm{mmol})$ in methanol $(5 \mathrm{~mL})$ at room temperature for $4 \mathrm{~h}$. After the mixture was washed with water, the organic phase was separated and dried over anhydrous $\mathrm{Na}_{2} \mathrm{SO}_{4}$. The solvent was removed and the resulting crude product was purified by column chromatography (silica gel, $\mathrm{CH}_{2} \mathrm{Cl}_{2} / \mathrm{MeOH}(99: 1)$ ) to afford Co-TPBP as a dark green solid (0.047 $\mathrm{g}, 89 \%)$. MALDI-TOF-MS $\mathrm{m} / \mathrm{z}(\%)$ : found 870.594 (100) $\left[\mathrm{M}^{+}\right]$, calcd $871.888\left(\mathrm{M}=\mathrm{C}_{60} \mathrm{H}_{36} \mathrm{~N}_{4} \mathrm{Co}\right)$; HRESI-MS $m / z$ : $\left[\mathrm{M}^{+}\right]$calcd for $\mathrm{M}=\mathrm{C}_{60} \mathrm{H}_{36} \mathrm{~N}_{4} \mathrm{Co}, 871.2272$; found 871.2273; $\lambda_{\text {abs }}\left(\varepsilon \times 10^{5}\right) 446(1.7), 595,640(0.8) \mathrm{nm}$. Upon excitation at $446 \mathrm{~nm}$, no emission peak was observed.

meso-Tetraphenyltetrabenzoporphyrinatotin (Sn-TPBP). Following a previously published procedure, ${ }^{36}$ a solution of TPBP (0.102 g, $0.125 \mathrm{mmol})$ and $\mathrm{SnCl}_{2} \cdot 2 \mathrm{H}_{2} \mathrm{O}(0.141 \mathrm{~g}$, $0.625 \mathrm{mmol}$ ) in dimethylformamide (DMF, $5 \mathrm{~mL}$ ) was treated with pyridine $(0.05 \mathrm{~mL})$ and refluxed for $4 \mathrm{~h}$. A blue green precipitate was formed and collected by filtration. After that, the resulting crude product was purified by column chromatography (silica gel, $\mathrm{CH}_{2} \mathrm{Cl}_{2} / \mathrm{MeOH}(99: 1)$ ) to afford Sn-TPBP as a deep green solid $(0.047 \mathrm{~g}, 90 \%)$. Due to incomplete purification of column chromatography, the achieved product was obtained with $>90 \%$ purity, based on ${ }^{1} \mathrm{H}$-NMR spectroscopy. ${ }^{1} \mathrm{H}-\mathrm{NMR}: \delta_{\mathrm{H}} 7.23(\mathrm{dd}, J=6.4,3.2 \mathrm{~Hz}, 8 \mathrm{H}), 7.43(\mathrm{dd}, J=6.4$, $3.2 \mathrm{~Hz}, 8 \mathrm{H}) 7.90(\mathrm{t}, J=7.6 \mathrm{~Hz}, 8 \mathrm{H}), 8.00(\mathrm{t}, J=7.6 \mathrm{~Hz} 4 \mathrm{H}), 8.34$ $(\mathrm{d}, J=7.6 \mathrm{~Hz}, 8 \mathrm{H}) ;{ }^{13} \mathrm{C}-\mathrm{NMR}: \delta_{\mathrm{C}} 116.5,125.6,127.2,127.6,129.7$, $129.8,133.9$, 137.4, 137.6, 137.8, 141.3, 141.6, 141.7, 141.8, 142.0; MALDI-TOF-MS $m / z$ (\%): found $966.292(100)\left[\mathrm{M}^{+}\right]$, calcd $965.679\left(\mathrm{M}=\mathrm{C}_{60} \mathrm{H}_{38} \mathrm{~N}_{4} \mathrm{O}_{2} \mathrm{Sn}\right) ; \lambda_{\mathrm{abs}}\left(\varepsilon \times 10^{5}\right) 430(0.3), 466(4.1)$, 612, 660(0.9) nm; $\lambda_{\text {em }}\left(\lambda_{\text {ex }}=466 \mathrm{~nm}\right) 665,745 \mathrm{~nm}$.

\section{Electrochemical studies}

Background current. A background cyclic voltammogram was obtained in an anhydrous solution $(10 \mathrm{~mL})$ of $0.1 \mathrm{M}$ 
tetrabutylammonium hexafluorophosphate $\left(\mathrm{TBAPF}_{6}\right)$ in DMF. A three-electrode one-compartment cell was used throughout the experiments. A glassy carbon electrode served as a working electrode while a Pt plate was used as a counter electrode. A silver wire coated with silver chloride $(\mathrm{Ag} / \mathrm{AgCl})$ was used as a quasi-reference electrode (QRE). The $\mathrm{Ag} / \mathrm{AgCl} \mathrm{QRE}$ was prepared using a procedure described elsewhere ${ }^{40}$ and externally calibrated with a ferrocene/ferrocenium redox couple using a potential of $0.72 \mathrm{~V} v s$. a normal hydrogen electrode (NHE) as a reference value. ${ }^{41}$ The cyclic voltammograms were recorded at potentials ranging from $0.00 \mathrm{~V}$ to $-2.00 \mathrm{~V}$ vs. a $\mathrm{Ag} / \mathrm{AgCl} \mathrm{QRE}$ at a scan rate of $50 \mathrm{mV} \mathrm{s}^{-1}$. The potential values were therefore reported with respect to the $\mathrm{Ag} / \mathrm{AgCl} \mathrm{QRE}$. The solution was purged with nitrogen $\left(\mathrm{N}_{2}\right)$ or $\mathrm{CO}_{2}$ for 20 min before each measurement with a flow rate of $0.2 \mathrm{~L} \mathrm{~min}^{-1}$. As a control experiment, constant-potential electrolysis of the electrolyte solution under $\mathrm{CO}_{2}$-saturated conditions in the absence of the catalyst for $20 \mathrm{~h}$ did not yield any $\mathrm{CO}_{2}$ reduction product.

\section{Electrochemical reduction of $\mathrm{CO}_{2}$}

The catalytic activity of the benzoporphyrins towards electrochemical reduction of $\mathrm{CO}_{2}$ was investigated by means of cyclic voltammetry and the constant-potential electrolysis using the above-mentioned electrochemical setup at potentials ranging from 0.00 to $-2.00 \mathrm{~V}$. Each cyclic voltammogram was collected from a $0.1 \mathrm{M} \mathrm{TBAPF}_{6}$ solution in anhydrous DMF containing $1.0 \mathrm{mM}$ benzoporphyrin $(10 \mathrm{~mL})$ at a scan rate of $50 \mathrm{mV} \mathrm{s}^{-1}$ under $\mathrm{N}_{2}$ - or $\mathrm{CO}_{2}$-saturated conditions. The solution was purged with $\mathrm{N}_{2}$ or $\mathrm{CO}_{2}$ for 20 min before each measurement with a flow rate of $0.2 \mathrm{~L} \mathrm{~min}^{-1}$. The constant-potential electrolysis of each benzoporphyrin was performed at ambient temperature using the above-mentioned electrochemical setup and at an applied potential of $-1.90 \mathrm{~V}$. After $20 \mathrm{~h}$, a $2 \mathrm{~mL}$ gas sample from headspace gas (total volume was $10 \mathrm{~mL}$ ) was taken from a reaction vial and analyzed by gas chromatography (GC) equipped with a thermal conductivity detector (TCD). Curves for CO obtained from the experiments were integrated to get the peak area, which was then used to calculate the amount of CO in the headspace using a pre-measured calibration curve.

\section{Conflicts of interest}

There are not conflicts to declare.

\section{Acknowledgements}

This research was partially supported by the Ratchadapiseksomphot Endowment Fund under Outstanding Research Performance Program, Chulalongkorn University (SciSuper III-003), and Graduate School of Chulalongkorn University (The $90^{\text {th }}$ Anniversary of Chulalongkorn University Fund, Ratchadaphiseksomphot Endowment Fund). Staff mobility was carried out with funding from the Grant for Join Funding, Ratchadapiseksomphot Endowment Fund. Electrochemical characterization of the materials and product analysis were done with funding from the Austrian Science Foundation (FWF) within the framework of the Wittgenstein Prize of Prof. Sariciftci (Solare Energie Umwandlung Z222-N19). E. P. is thankful for the financial support from the FWF project P29645-N36.

\section{References}

1 A. Michele, Carbon Dioxide as Chemical Feedstock, Wiley-VCH Verlag GmbH\&Co., 2010.

2 J. P. Collin and J. P. Sauvage, Coord. Chem. Rev., 1989, 93, 245-268.

3 H. Khoshro, H. R. Zare, A. Gorji, M. Namazian, A. A. Jafari and R. Vafazadeh, J. Electroanal. Chem., 2014, 732, 117-121.

4 K. Ghobadi, H. R. Zare, H. Khoshro, A. Gorji and A. A. Jafari, C. R. Chim., 2018, 21, 14-18.

5 H. Khoshro, H. R. Zare, A. A. Jafari and A. Gorji, Electrochem. Commun., 2015, 51, 69-71.

6 D. W. Agnew, M. D. Sampson, C. E. Moore, A. L. Rheingold, C. P. Kubiak and J. S. Figueroa, Inorg. Chem., 2016, 55, 12400-12408.

7 C. Cometto, R. Kuriki, L. Chen, K. Maeda, T. C. Lau, O. Ishitani and M. Robert, J. Am. Chem. Soc., 2018, 140, 7437-7440.

8 C. W. MacHan and C. P. Kubiak, Dalton Trans., 2016, 45, 17179-17186.

9 M. Robert, H. Rao and J. Bonin, ChemSusChem, 2017, 10, 4447-4450.

10 H. Rao, J. Bonin and M. Robert, Chem. Commun., 2017, 53, 2830-2833.

11 M. H. Reineke, T. M. Porter, A. L. Ostericher and C. P. Kubiak, Organometallics, 2018, 37, 448-453.

12 A. Zhanaidarova, H. Steger, M. H. Reineke and C. P. Kubiak, Dalton Trans., 2017, 46, 12413-12416.

13 H. Takeda, C. Cometto, O. Ishitani and M. Robert, ACS Catal., 2017, 7, 70-88.

14 A. J. Morris, G. J. Meyer and E. Fujita, Acc. Chem. Res., 2009, 42, 1983-1994.

15 S. Kumar, M. Y. Wani, C. T. Arranja, J. D. A. E Silva, B. Avula and A. J. F. N. Sobral, J. Mater. Chem. A, 2015, 3, 1961519637.

16 H. L. Anderson, Chem. Commun., 1999, 2323-2330.

17 F. C. Krebs and H. Spanggaard, Sol. Energy Mater. Sol. Cells, 2005, 88, 363-375.

18 J. S. Lindsey, Acc. Chem. Res., 2010, 43, 300-311.

19 K. M. Kadish, Progress in Inorganic Chemistry, Wiley-VCH Verlag GmbH\&Co., 1986, vol. 34.

20 Y. Chen and L. Wang, Polyhedron, 1993, 12, 1353-1360.

21 K. M. Kadish, O. S. Finikova, E. Espinosa, C. P. Gros, G. De Stefano, A. V. Cheprakov, I. P. Beletskaya and R. Guilard, J. Porphyrins Phthalocyanines, 2004, 08, 1062-1066.

22 W. Keawsongsaeng, J. Gasiorowski, P. Denk, K. Oppelt, D. H. Apaydin, R. Rojanathanes, K. Hingerl, M. Scharber, N. S. Sariciftci and P. Thamyongkit, Adv. Energy Mater., 2016, 6, 1-11.

23 G. Zanotti, N. Angelini, G. Mattioli, A. M. Paoletti, G. Pennesi, G. Rossi, D. Caschera, L. De Marco and G. Gigli, RSC Adv., 2016, 6, 5123-5133. 
24 D. Solonenko, J. Gasiorowski, D. Apaydin, K. Oppelt, M. Nuss, W. Keawsongsaeng, G. Salvan, K. Hingerl, N. Serdar Sariciftci, D. R. T. Zahn and P. Thamyongkit, J. Phys. Chem. C, 2017, 121, 24397-24407.

25 G. Ramírez, M. Lucero, A. Riquelme, M. Villagrán, J. Costamagna, E. Trollund and M. J. Aguirre, J. Coord. Chem., 2004, 57, 249-255.

26 G. Ramírez, G. Ferraudi, Y. Y. Chen, E. Trollund and D. Villagra, Inorg. Chim. Acta, 2009, 362, 5-10.

27 K. Ogura and I. Yoshida, J. Mol. Catal., 1988, 47, 51-57.

28 G. Zheng, M. Stradiotto and L. Li, J. Electroanal. Chem., 1998, 453, 79-88.

29 D. Behar, T. Dhanasekaran, P. Neta, C. M. Hosten, D. Ejeh, P. Hambright and E. Fujita, J. Phys. Chem. A, 1998, 102, 2870-2877.

30 N. Sonoyama, M. Kirii and T. Sakata, Electrochem. Commun., 1999, 1, 213-216.

31 C. Maeda, Y. Miyazaki and T. Ema, Catal. Sci. Technol., 2014, 4, 1482-1497.

32 O. S. Finikova, A. V Cheprakov, I. P. Beletskaya, P. J. Carroll and S. A. Vinogradov, J. Org. Chem., 2004, 69, 522-535.
33 A. Vogler, H. Kunkely and B. Rethwisch, Inorg. Chim. Acta, 1980, 46, 101-105.

34 M. Strohmeier, A. M. Orendt, J. C. Facelli, M. S. Solum, R. J. Pugmire, R. W. Parry and D. M. Grant, J. Am. Chem. Soc., 1997, 7863, 7114-7120.

35 A. B. Lysenko, P. Thamyongkit, I. Schmidt, J. R. Diers, D. F. Bocian and J. S. Lindsey, J. Porphyrins Phthalocyanines, 2006, 10, 22-32.

36 S. Wang, I. Tabata, K. Hisada and T. Hori, Dyes Pigm., 2002, 55, 27-33.

37 G. F. Manbeck and E. Fujita, J. Porphyrins Phthalocyanines, 2015, 19, 45-64.

38 Y. Fang, M. O. Senge, E. Van Caemelbecke, K. M. Smith, C. J. Medforth, M. Zhang and K. M. Kadish, Inorg. Chem., 2014, 53, 10772-10778.

39 A. M. Stolzenberg and L. J. Schussel, Inorg. Chem., 1991, 30, 3205-3213.

40 A. W. Hassel, K. Fushimi and M. Seo, Electrochem. Commun., 1999, 1, 180-183.

41 C. G. Zoski, Handbook of Electrochemistry, Elsevier B.V., 1st edn, 2007. 